\title{
ACERCA DEL DERECHO DE LA MUJER A GOBERNAR EN FRANCISCO SUÁREZ
}

\author{
MAURICIO LECÓN ROSALES \\ Universidad Panamericana
}

\begin{abstract}
RESUMEN: En el libro III del De legibus, Francisco Suárez afirma que una mujer puede heredar y ostentar la potestad política sobre una comunidad. El varón posee un dominio natural sobre la mujer porque ella fue creada a partir de aquél, según el relato del Génesis. De acuerdo con Francisco Suárez, existe un derecho natural de la mujer a gobernar. Si esto es así, es falso que la mujer posea una naturaleza inferior al varón que le condiciona a únicamente heredar a su prole la potestad de gobierno, pero no a ejercerla.
\end{abstract}

PALABRAS CLAVE: Francisco Suárez; reina; dominio; derecho natural.

\section{Francisco Suárez on Women's Right to Rule}

ABSTRACT: In book III of De legibus, Francisco Suárez claims that women can inherit and hold the political power to rule over a community. Men possess a natural dominion over women since women were created from them, according to Genesis. According to Francisco women possess a natural right to rule. If it is so, then it is false that women have an inferior nature to men by which they can only to inherit to their offspring the power to rule, but they cannot exert it.

KEY WORDS: Francisco Suárez; Queen; Dominion; Natural Right.

\section{INTRODUCCIÓN}

En De legibus III, IX, 7, Francisco Suárez se pregunta si la potestad legislativa puede residir en una mujer o si una mujer puede heredar el reino. Aunque parezcan dos preguntas distintas, en realidad, es un único problema. Por un lado, el poder para gobernar una comunidad perfecta incluye la capacidad para producir leyes con las que se pueda obligar a los súbditos ${ }^{1}$. Por el otro, el poder político del reino sólo se transfiere por sucesión hereditaria — salvo en el caso del primer soberano quien debió recibirlo inmediatamente de la comunidad $-^{2}$. Lo que se pregunta Suárez, entonces, es sobre la posibilidad de que una mujer pueda heredar y ejercer la potestad de dar de leyes a una comunidad, esto es, de convertirse en una reina soberana. Prueba de ello es que Suárez aclara que se refiere a una mujer que recibe el nombre de reina por derecho propio a través de la sucesión, no a la figura de una reina consorte —expresión que no utiliza-. La mujer que es llamada reina sólo «a causa de su matrimonio con el rey [...] no tiene el poder de dar leyes, pues su

1 La ley «es como el instrumento por medio del cual el príncipe influye moralmente en el estado para gobernarlo», en: SuÁrez, F., Tractatus de legibus ac Deo legislatore, I, c. 7, n. 5, (Opera omnia, París, Vivès, 1856, t. 5).

2 Cf. Ibid., III, c. 4 , n. 3. 
dignidad no es dignidad de jurisdicción, sino sólo de honor. De ahí que [una reina tal] no sólo carece del poder para legislar, sino también [del poder] para gobernar» ${ }^{3}$.

Suárez responde afirmativamente al cuestionamiento inicial diciendo que «es cosa cierta que una reina que tiene dominio del reino puede dar leyes lo mismo que el rey» ${ }^{4}$. Al respecto, la argumentación de Suárez no es muy elaborada. Básicamente, Suárez justifica la legitimidad de una reina apelando a las Partidas de Alfonso X e invocando la autoridad de juristas y canonistas de la época - Inocencio IV, Bernardo de Montmirat (i.e. Abbas antiquus), Antonio Corset, Baldo degli Ubaldi, entre otrosEl resto de la argumentación consiste en desechar algunas objeciones interpuestas y desestimar la posibilidad de que una reina pueda transferir el reino a su marido.

A esta breve indagación que hace Suárez, me parece, subyace un compromiso antropológico más fuerte, a saber, una consideración más noble de la feminidad. La cual, si se articula con otras tesis de la filosofía jurídica del Eximio, arroja una concepción de la naturaleza femenina exenta de impedimentos naturales para poseer y ejercer una facultad típicamente masculina: el dominio político.

A continuación reconstruiré los principales elementos teóricos $-\mathrm{y}$ sus implicaciones-que conforman la posición suareciana, según la cual es de derecho natural la posibilidad de que una mujer sea reina y gobierne una comunidad perfecta, ya que por naturaleza todo ser humano posee el dominio o potestad moral para hacerlo ${ }^{5}$. Para ello haré cuatro cosas. Primero, expondré la la connaturalidad del dominio al ser humano, según Suárez. En segundo lugar, argumentaré que en Suárez el dominio pertenece a la naturaleza humana secundum se. Después defenderé que para Suárez la feminidad no es una condición que prevenga a ciertos individuos de poseer y usar su dominio. Por último, concluiré que la ley natural garantiza, de algún modo, la posibilidad de que cualquier ser humano pueda ejercitar su dominio político.

\section{LA FACUltad DE DOMinio ES NATURAL AL SER HUMANO}

De acuerdo con Francisco Suárez, un individuo puede mandar sobre otros gracias a que posee un dominio sobre aquéllos. Suárez, empero, distingue que una cosa es la capacidad de dominio, otra la potestad de dominio y otra su uso o ejercicio. Los últimos elementos suponen, necesariamente, los primeros ${ }^{6}$. Se puede tener la capacidad para gobernar (regni), pero carecer de la potestad para hacerlo y no ejercitar dicha capacidad. Asimismo, un rey que ha sido privado ilegítimamente de su reino, tiene la capacidad y la potestad para gobernar, aunque

$3 \quad$ Ibid., c. 9 , n. 7.

4 Ibid., c. 9 , n. 8 .

5 Para un estudio pormenorizado de las implicaciones modernas que tiene la noción suareciana de ius, véase: Ibáñez Ruiz del Portal, E., «Francisco Suárez y los derechos humanos. Corrientes historiográficas y perspectivas críticas actuale», en: Pensamiento, vol. 74 núm. 279 , 2018, pp. 221-235.

6 «Tria possumus in hoc dominio dinstiguere, scilicet, capacitatem, potestatem et usum seu statum dominandi. Haec enim tria adeo distincta sunt, ut sint etiam separabilia, non quidem mutuo, quia posterioria necessario suponunt priora, tamen en contrario priora possunt e posterioribus sejungi», en: SuÁREz, F., De opere sex dierum III, c. 16, n. 5 (Opera omnia, París, Vivès, 1856, t. 3). 
no pueda practicarlo. Todo agente que efectivamente usa o ejercita su potestad de dominio sobre otros seres humanos debe tener no sólo la capacidad para hacerlo, sino también la potestad. De la misma manera en que nadie tiene la potestad para gobernar si no tiene también la capacidad para hacerlo.

El dominio en Francisco Suárez es fundamentalmente una potestad o poder ${ }^{7}$. La comprensión común del término (juxta communem et receptum morem) consiste en comprender el dominio como un acto primero y como principio activo. Por eso, el dominio no puede reducirse al uso porque éste es considerado un acto segundo que procede de un acto primero; tampoco puede ser la capacidad remota porque ésta se comporta como una potencia pasiva. Más bien se dice que el dominio es una facultad moral porque no añade nada al sujeto más que la potestad para hacer algo lícitamente sin perjuicio a otro ${ }^{8}$.

La capacidad natural del ser humano para dominar a otros seres es un poder moral de los individuos, ya que constituye una condición necesaria para que los individuos alcancen el fin que la naturaleza les ha impuesto. De ahí que Suárez llame a la potestad de dominio un derecho (ius), en tanto que constituye un poder moralmente legítimo para que las personas puedan procurarse lo necesario para su provecho, conservación y perfeccionamiento, pues «con toda propiedad suele llamarse ius al poder moral que cada uno tiene sobre lo suyo o sobre lo que se le debe [...] luego la acción o facultad moral que cada uno tiene sobre su cosa o sobre la cosa que de algún modo le pertenece se llama derecho y ese parece ser propiamente el objeto de la justicia» ${ }^{9}$.

La cualidad moral del dominio pertenece a la naturaleza y esencia humanas en virtud de haber sido creadas a imagen y semejanza de Dios. Dicha condición se manifiesta, fundamentalmente, en la razón y en la libertad de las personas; lo cual convierte a estas propiedades en los elementos imprescindibles para que una persona cualquiera pueda tener el derecho a dominar a otros ${ }^{10}$. Las implicaciones de esto son enormes. Primero, esto significa que las criaturas inferiores están naturalmente impedidas para poseer esta facultad o derecho ${ }^{11}$. El uso que las bestias hacen, por ejemplo, de otras especies o de las plantas no cuenta como un auténtico dominio. Adicionalmente, esto implica que el dominio no es un privilegio especial que Dios concedió a los seres humanos ni una facultad que procede de las leyes humanas, sino algo que emana de su propio ser ${ }^{12}$. La facultad moral por la que el ser humano puede usar, disponer y/u ordenar a otras criaturas no es una cualidad sobrenatural, sino una capacidad que emana de su peculiar modo de ser. Más importante aún

7 «ex illis tribus [capacitas, potestas et usu], dominium proprie consistere in secundo»: Ibid., III, c. 16, n. 5 .

8 «quod jus potestatem moralem merito appellamus, quia non addit homini aliquam entitatem, vel qualitatem, sed solam moralem facultatem ut licite et sine alterius injuria possit uti rebus illis, quarum est dominus»: Ibid., III, c. 16, n. 9.

9 SuÁrez, F., De legibus, I, II, 5.

10 "capacitatem domini convenire homine naturaliter ex eo quod ad imaginem Dei factus est. Hoc per se manifestum est, nam homo propter rationem, et libertatem est ad imaginem Dei, et propter easdem proprietates est capax dominii», en: Sú́REZ, F., De opere sex dierum III, c. 16, n. 6.

11 Ver ibid., III, c. 16, n. 1-2.

12 «[dominium] naturale dici, quia naturam ipsam consequitur, estque ei quodammodo debitum, est usus ejus naturaliter est, nisi specialiter prohibeatur»: Ibid., III, c. 16, n. 9. 
es el hecho de que si el dominio concierne a la naturaleza humana secundum se -i.e. tomada en sí misma con independencia de su situación-, entonces el poder de dominio es común a la naturaleza pre y postlapsaria del ser humano, lo cual desestima la tesis de que el dominio es producto del pecado original y, por tanto, propio de la naturaleza caída del hombre ${ }^{13}$. En cambio, suscribe la compatibilidad entre el dominio y la naturaleza pura del ser humano, con lo cual Suárez aventura que en el estado de inocencia o naturaleza ${ }^{14}$ existieron —o pudieron hacerlo— todas las especies de dominio, salvo una: el dominio de servidumbre.

Las especies de dominio se distinguen entre sí dependiendo de los seres sobre los cuales se ejerce y los actos para los cuales faculta. La capacidad natural de dominio puede versar sobre las creaturas inferiores al ser humano o sobre sus congéneres ${ }^{15}$. La capacidad humana para dominar a los entes inferiores se denomina dominio de propiedad (dominium proprietatis) y consiste en el derecho del hombre a usar de las cosas según todos los modos posibles y para su propio beneficio ${ }^{16}$. En cambio, la capacidad humana de dominar a otros individuos de su misma especie puede manifestarse como un dominio de propiedad - para los casos de servidumbre en los que el amo está facultado para disponer de la persona y acciones del siervo- o como un dominio de gobierno (dominium gubernationis) o directivo (dominium directivum), por el cual el gobernante dirige las acciones de los súbditos y discierne lo que les conviene en beneficio de ellos mismos. Éste último puede ser de tres tipos, según se trate de una comunidad doméstica o civil: el dominio del varón sobre su mujer, el dominio del padre sobre los hijos y el dominio de un individuo sobre una comunidad perfecta. El dominio sobre la mujer y los hijos pertenecen a la especie de dominio económico (potestas oeconomica), mientras que el dominio sobre una comunidad política reunidas voluntariamente es denominado dominio político (potestas politica) o de jurisdicción (dominium iurisdictionis) ${ }^{17}$. La potestad

13 «bona propria status innocentiae per peccatum amissa sunt, et e contrario illa, quae post peccatum permanserunt, naturam humanam secundum se spectatam consequuntur. Sed dominium externarum rerum, tam animantium, quam non ani-mantium in homine post peccatum mansit, ut ipso usu, et ratione constat: ergo non fuit aliquid peculiare pro statu innocentiae datum, sed mere naturale»: Ibid., III, c. 16, n. 2 .

14 Recordemos que para Suárez la naturaleza pura no es un estado real, sino una hipótesis teológica. Para un estudio más preciso acerca de la noción de estado de naturaleza en Suárez y otros autores, ver CASTILla URBano, F., «El concepto de «estado de naturaleza» en la escolástica española de los Siglos XVI y XVII», en: Anuario filosófico, núm. 12, 1995, pp. 425-445.

15 «hominem, ut est ad imaginem Dei, non solum habere capacitatem dominandi brutis animalibus, sed etiam rationalibus, id est, hominibus. Quia per rationem non solum potest homo discernere, ordinare ac disponere ea, quae pertinent ad animalia bruta, sed etiam quae ad homines spectant, et multo facilius, ac proprius potest illis imperare», en: SuÁREz, F., De opere sex dierum III, c. 16, n. 7 .

16 Ver SuÁrez, F., De statu perfectionis et religionis l. VIII, c. V, n. 29 (Opera omnia, París, Vivès, 1859 , t. 15).

17 Ver SuÁrez, F., De opere sex dierum V, c. 7, nn. 9 ss. Cf. SuÁrez, F., De legibus I, c. VIII, n. 4. Ahí aparece una variación en la terminología, pues Suárez abandona las categorías de dominium directivum y dominium gubernativum, en: "Potestas ergo praeceptiva quasi generica est, quae in duas species distinguenda est, quas potestatem oeconomicam et politicam, vel potestatem dominativam et jurisdictionis appellare possumus [...] ut solent etiam distingui ab auctoribus distinguentibus dominium in dominium jurisdictionis et proprietatis [...] Possunt autem distingui hae potestates circa personas, et aliquo modo circa res alias, circa quas proprius invenitur potestas 
que tiene un padre sobre su hijo surge pasivamente por modo de relación, es decir, puesto el fundamento de la paternidad —i.e. la concepción del hijo- surge necesariamente en el padre su potestad para dirigir y educar al hijo. En cambio, la facultad para dominar a su mujer y el dominio político exigen un pacto entre las partes. En el caso del matrimonio, la mujer acepta subordinarse domésticamente a su esposo en orden al gobierno de la casa y de la familia. Mientras que en el caso del dominio político, los familias de la comunidad y sus miembros eligen someterse a la voluntad de un gobernante concediéndole la fuerza para castigar y ordenar a los individuos a través de leyes para el beneficio de la comunidad misma ${ }^{18}$.

En el estado de inocencia, el ser humano también tuvo dominio. Francisco Suárez elaboró la reflexión más importante acerca de la vida política del hombre en el estado de inocencia. Dicho esfuerzo cumple una función metodológica en su filosofía, pues se sirve del estado de inocencia como un ejercicio heurístico para evaluar la necesidad y naturaleza de ciertas capacidades, conductas e instituciones humanas. Así, Suárez afirma que en el estado de inocencia no existió una comunidad doméstica entre amo y esclavo, pues la falta de libertad que encierra es una pena o castigo que no debieron padecer los hombres si hubieran estado exentos de pecado $^{19}$. De ahí que el dominio de servidumbre no pertenezca a la naturaleza humana secundum se, sino que sólo es una institución apta para la naturaleza caída y pertenece al derecho de gentes la permisión o prohibición de la servidumbre bélica o voluntaria ${ }^{20}$. En cambio, Suárez defiende que en el estado de inocencia existió una sociedad económica y que, de haber perdurado, necesariamente habría surgido una comunidad política entre los descendientes de Adán y Eva. Esto implica que el dominio doméstico del padre de familia sobre la esposa y sobre los hijos, así como el dominio político de un gobernante sobre su comunidad son enteramente compatibles con la naturaleza humana incólume o pura. A diferencia de lo que

dominii quam jurisdictionis; tamen suo modo etiam haec circa illas versatur, vel secundario, et per consecutionem, vel per modum administrationis». En cambio, en el n. 5 de ese mismo capítulo, Suárez distingue entre poder dominativo (potestas dominativa) y poder de jurisdicción (potestas iurisdictionis). Bajo el primero incluye todas las especies de dominio doméstico y de servidumbre y, en cambio, al segundo lo identifica con el dominio político, abandonando el uso genérico que había hecho de este nombre en De opere sex dierum V, c. 7, n. 11. En el presente trabajo sigo la clasificación y terminología empleada en De opere. Por ello, no hago la distinción entre potestad y dominio; asumo que la potestad política y económica son dos tipos de dominio y me refiero en el sentido a la primera para significa lo que Suárez denomina potestad de jurisdicción en De legibus I, c. VIII, nn. 4 ss.

18 Ver SuÁrez, F., De opere sex dierum V, c. 7, n. 12 y Sú́ReZ, F., De legibus I, c. VIII, n. 5.

19 A esto se refiere Suárez cuando afirma que el dominio humano en el estado de caída excede, materialmente, al dominio en el estado de inocencia. Ver Suárez, F., De opere sex dierum III, c. 16, n. 4 .

20 John Doyle (ver Doyle, J., «Suárez on Human Rights», en: Collected Studies on Francisco Suárez, S.J, (1548-1617), Victor M. Salas (ed.), Leuven University Press, Leuven, p. 350) hace notar que aunque Suárez acepta y justifica la esclavitud, la considera una condición contraria a la dignidad humana que ha sido introducida, accidentalmente, por el derecho de gentes como un castigo severo, pero inferior a la muerte (ver SuÁrEz, F., De virtute et statu religionis tr. VII, l. 2, c. 12, n. 17 (Opera omnia, París, Vivès, 1859, t. 13)). Inclusive, en algún lugar sugiere la necesidad de restringirla por considerarla intolerable (ver Tractatus de charitate d. 7, s. 2, n. 2). Ver también GaETano, M. T., «What Kind of Corporeal or Political Life Men Would Have Professed in the State of Innocence», en: Journal of Markets \& Morality, vol. 15, núm. 2, pp. 527-563. 
sucede en el caso de servidumbre, la subordinación de los hijos (involuntaria en esta caso), la esposa y la comunidad no es en detrimento de su libertad ${ }^{21}$. Por el contrario, todas estas son instituciones para la comparecencia de la libertad humana en la medida en que son indispensables para que las personas sobrevivan, se conserven, se propaguen y alcancen el fin al que están ordenadas. Suárez advierte que el dominio político en el estado de inocencia debería haber sido fundamentalmente directivo y no coactivo, pues los ciudadanos habrían sido máximamente dóciles y no habría habido castigos que impartir. En cualquier caso, el solo hecho de que el dominio de jurisdicción haya sido posible en el estado de inocencia es signo de que éste conviene intrínsecamente a la naturaleza humana porque surge de su esencia al margen de su condición de inocencia o caída, pues vivir en una comunidad política es apto no sólo para sortear la indigencia humana, sino también para llevar una vida más gozosa y una interacción (communicationem) más honesta ${ }^{22}$.

\section{El DOMINIO DE JURISDICCIÓN SE TRANSMITE SEGÚN LAS COSTUMBRES HUMANAS}

La sociabilidad natural del ser humano ${ }^{23}$ lo ordena a vivir en una comunidad perfecta. El ser humano es incapaz de proveerse, por sí mismo, todos los bienes necesarios para su conservación y para el fin al que está ordenado. Por eso su naturaleza lo impele, inicialmente, a conformar una sociedad entre marido y mujer mediante la cual la especie puede conservarse y propagarse. La familia es la comunidad fundamental de los seres humanos y la matriz de cualquier otra comunidad que puedan formar. A partir de ella, surge naturalmente la sociedad de los padres con los hijos, quienes viven bajo el dominio de aquéllos para superar sus indigencia temprana y para ser educados rectamente ${ }^{24}$. La eventual emancipación de los hijos para formar sus respectivas comunidades domésticas trae consigo la multiplicación de las familias o casas (domi). Dicha proliferación resulta en una unidad social más compleja denominada tribu (tribus) o aldea (pagus). Dicha comunidad exige la unión moral de las familias, esto es, el acuerdo explícito o implícito mediante el que los miembros de cada familia pactan la subordinación a un poder superior ${ }^{25}$. Esta comunidad es más perfecta que la familia, pero

21 Cintia Faraco defiende que, según Suárez, en el estado de inocencia no existió ninguna necesidad de crear una sociedad política. La comunidad política sólo era conveniente, pero la elección de congregarse por parte del hombre perfecto pre-caída debió haber sido una manifestación de su libertad. Al respecto, me parece, conviene matizar que la necesidad ausente en el estado de inocencia es una necesidad metafísica. Sin embargo, es posible afirmar que existió una necesidad moral de los hombres a reunirse con otros. Esto es, una inclinación natural que los movió a reunirse voluntariamente en orden a su fin. Considero importante, empero, llamar a dicha inclinación una necesidad, pues Suárez se resiste a pensar que los seres humanos — sea en el estado de inocencia o caída- pueden alcanzar su felicidad al margen de cualquier tipo de comunidad. Cf. FARACo, C., «Faciamus hominem: reflexión sobre el libro V del Tractatus de opere sex dierum de Suárez», en: Cauriensia, vol. 12, 2017, pp. 153-168.

22 Ver SuÁRez, F., De opere sex dierum V, c. 7, n. 6.

23 Ver De legibus III, c. I, n. 3.

24 Ver ibid.

25 Ver SuÁREz, F., De opere sex dierum V, c. 7, n. 3. 
imperfecta respecto de la ciudad. La razón de esto es que la aldea es insuficiente tanto para proveer los servicios y oficios necesarios para la vida humana como para proporcionar a las personas una educación recta y el conocimiento de las cosas necesarias ${ }^{26}$. Signo de lo anterior es que la tribu o aldea posee una unidad imperfecta porque es insuficiente para garantizar las necesidades últimas de la vida humana. En las comunidades imperfectas, lo que vincula a sus miembros es su condición de inferioridad respecto de una misma instancia. En cambio, en una comunidad perfecta, los individuos se congregan como «miembros principales para formar un cuerpo político ${ }^{27}$. Esto significa que la sumisión a un mismo poder no es el fundamento de la asociación, sino el resultado de ésta. Los miembros de una comunidad perfecta constituyen un solo cuerpo gracias al vínculo moral que los une después de pactar reunirse para perseguir sus fines y confiar a una cabeza el poder para gobernarlos en beneficio de todos. Quien gobierna una ciudad recibe el dominio de jurisdicción que lo faculta para dirigir a los individuos hacia al bien común mediante leyes ${ }^{28}$. El soberano debe gozar del poder para crear leyes, ya que éste es el principal acto con que se gobierna una comunidad política, pues el poder de jurisdicción, en tanto poder público y ordenado a la comunidad, tiene la virtud de obligar a los individuos en la medida y proporción en que ha sido confiado ${ }^{29}$.

En una comunidad perfecta es necesario un soberano con el poder para dictar leyes. La comunidad política de los hombres «no puede conservarse sin la justicia y la paz, y éstas sin un gobernante que tenga poder de mando y coacción; luego en la sociedad humana es necesario un principio político que la conserve en su misión (illa in officio contineat) ${ }^{30}$. La necesidad de que exista un poder a cargo del gobierno de la comunidad civil nace de la necesidad de conservar la unidad entre los individuos. Si no existiera dicha instancia, entonces la comunidad se disgregaría, pues los individuos tienden a mirar por su conveniencia particular en vez de atender al bien común. Luego en una comunidad perfecta es necesario un poder público al que le corresponda por oficio buscar y procurar el bien común a través de la promulgación de leyes.

Las leyes con las que se dirige a los miembros de una comunidad deben estar, por su esencia y sustancia, dirigidas al bien común ${ }^{31}$. Para que las leyes impuestas por un gobernante sean justas y obliguen efectivamente a los ciudadanos, deben tener como fin el bien de toda la comunidad —entendida como una corporación-. Esto es evidente en las leyes que versan sobre bienes que no pertenecen a ningún

26 «In tali communitate non est propria iurisdictio, nec vis coactiva [...] Huius aute ratio est imperfectio quasi naturalis talis communitatis, quia non sibi sufficit ad felicitatem humana comparandam eo modo, quo humano modo coparari potest, vel (ut clarius dicatur) partes talis communitatis non sisi invice praestant sufficiens subsidium, vel mutuu iuvamen, quo indiget human societas ad suu finem, vel ad su suam conservationem», en: SuÁrEz, F., De legibus I, c. VI, n. 22.

27 Ver ibid. I, c. VI, n. 20.

28 "potestas autem civilis ex natura rei est in ipsa communitate et per illam in hunc vel illum principem translata est, voluntate ipsius communitatis, eam (ut sic dicam) tanquam rem suam alteri donantis», en: Suárez, F., Defensio fidei Catholicae adversus anglicanae sectae errores III, c. 3, n. 13, (Opera omnia, París, Vivès, 1859, t. 24).

29 Ver Suárez, F., De legibus I, c. I, n. 6 y c. VIII, n. 7.

30 SuÁrez, F., Defensio fidei III, c. 1, n. 4.

31 Ver SuÁrez, F., De legibus III, c. I, n. 5 y I, c. VII. 
particular como los templos, magistraturas o espacios públicos. Sin embargo, existen auténticas leyes cuya materia próxima es algún bien particular. Esto es así — piensa Suárez- porque el bien particular puede concernir al bien de toda la comunidad por redundancia en determinado tiempo, lugar y comunidad. Por ejemplo, las leyes tributarias se imponen sólo a una parte de la comunidad por razón de la condición de algunas personas y en beneficio del Estado (republica). «[P]ara la ley no se requiere que se dé para toda la comunidad —digámoslo asítotalmente, porque en una parte de ella puede haber comunidad suficiente y fundamento suficiente para la perpetuidad de la ley para que ésta proceda de una jurisdicción que sea política y que se refiera inmediatamente al gobierno común ${ }^{32}$. En ocasiones existe una razón suficiente para imponer carga a una parte de la comunidad por fuera de su cargo u oficio - artesanos, militares, estudiantes-, de su clase o condición — plebeyos, nobles, judíos, conversos- o para los que habitan un determinado barrio o parte de la ciudad ${ }^{33}$. En todos los casos, los sectores pueden constituir una generalidad suficiente para la justicia de la ley, siempre que su carga o privilegio sea útil y conveniente al bien de la comunidad en general.

El soberano recibe de la comunidad el poder para gobernar y crear leyes. De acuerdo con Suárez, la potestad de jurisdicción o el dominio político no reside en un solo hombre en particular. Por naturaleza todos los seres humanos nacen igualmente libres y, por tanto, ninguno tiene una jurisdicción política o dominio sobre otro; si lo hubiera, no existiría razón alguna para atribuirle el dominio a un individuo en vez de otro ${ }^{34}$. Suárez concluye, entonces, que por derecho natural el dominio de jurisdicción reside exclusivamente en una comunidad humana perfecta, esto es, en un colectivo que no es un mero agregado de hombres, sino que constituye un único cuerpo político en virtud de que sus miembros deliberadamente se unieron para ayudarse mutuamente. La congregación de los individuos en un solo cuerpo indefectiblemente reclama la existencia de una cabeza. Es absurdo e inútil imaginar que los hombres quisieran reunirse de esa forma sin quedar sujetos a un poder político, «lo primero, porque la unidad de este cuerpo en gran parte resulta de la sujeción a un mismo régimen y a un poder superior; y lo segundo porque en otro caso ese cuerpo no podría ser dirigido a un mismo fin y al bien común ${ }^{35}$. De esta manera se confirma que el poder temporal es otorgado por la comunidad para el bien de la comunidad, pues «es evidentísimo que no ha sido dado para utilidad del príncipe [...] Por eso a los reyes se les llama funcionarios del estado. [...] Luego deben hacer uso de su poder en bien del estado, del cual y para el cual lo han recibido. Por eso [...] el tirano se diferencia del rey en que aquél en su gobierno busca su propia utilidad ${ }^{36}$.

32 Ibid., I, c. VI, n. 24.

33 Ver ibid., I, c. VI, n. 24 y c. VII, nn. 8 ss.

34 Aunque pudiera afirmarse que Adán tuvo dicha potestad en su calidad de primer hombre, Suárez niega que existan razones naturales o evidencia revelada para presumir que Dios dio inmediatamente a Adán el poder para dominar o regir políticamente a su estirpe. Adán gozó, únicamente, de un dominio económico sobre su esposa e hijos, el cual, empero, no le otorgó el poder político sobre las familias que, eventualmente, se formaron. Ver De legibus III, c. II, n. 3.

35 Ibid., III, c. II, n. 4.

36 Ibid., I, c. VII, n. 7. 
La manera en que se organiza y transmite el poder político se establece por costumbre según el derecho de gentes ${ }^{37}$. Ciertamente, la naturaleza humana inclina a todos los hombres a asociarse y someterse a un poder en aras de la felicidad a la que cada uno está llamado. Sin embargo, la concreción fáctica de ese impulso natural está sujeto a las prácticas y convenciones humanas. En primer lugar, esto implica que la naturaleza social del ser humano no lo inclina a la búsqueda de un único poder sobre toda la especie. Semejante gobierno no sólo es innecesario para la conservación de la humanidad, sino que sería inconveniente porque un reino tal sería ingobernable. Más importante aún, empero, es que el principio último del poder político no es la naturaleza humana, sino la comunidad de hombres. Luego nadie ha recibido el poder civil sobre todos los hombres, ya que «ni todos los hombres se reunieron alguna vez para conferírselo a algún soberano sobre todo el mundo, ni sabemos que Dios se lo confiriese a alguno» ${ }^{38}$. Así, el dominio de jurisdicción siempre ha estado fragmentado en diversas comunidades históricas, las cuales se han formado, dividido o desaparecido por el consentimiento de sus miembros. En segundo lugar, Suárez reconoce que la articulación del poder político en una estructura efectiva de gobierno está a merced de la prudencia y la libre voluntad humana ${ }^{39}$. La necesidad natural de que exista un poder político no prefigura el modo de organización de dicho poder, ya que «en virtud de la sola razón natural no se determina el poder político (principatus politicus) a la monarquía o a la aristocracia simple o mixta, pues no existe razón para establecer que un modo específico de gobierno (regimen) es necesario ${ }^{40}$. Prueba de esto es que históricamente algunas comunidades han adoptado diferentes formas de gobierno sin haber obrado contra la naturaleza humana, ya que cada comunidad puede organizar su poder político de la manera en que mejor convenga al bien común ${ }^{41}$. Finalmente, debe afirmarse que para Suárez tampoco pertenece a la naturaleza humana establecer el modo de entrega y transmisión del poder político ${ }^{42}$. Habíendose congregado los individuos en una comunidad política a través de un pacto social, existe una primera traslación del poder por parte de la comunidad al príncipe, la cual acaece por vía de un pacto

37 La prevalencia del derecho de gentes y las costumbres humanas en la determinación del poder político ha sido entendida como una virtud de la teoría política suareciana, en la medida en que la especulación se mantiene anclada a las condiciones históricas del ser humano. Ver Font Oporto, Pablo, «La facticidad de la filosofía política de Francisco Suárez: un camino hacia otra Modernidad», en: Pensamiento. Revista de Investigación e Información Filosófica, vol. 74, n. 279 Extra. 2018, p. 179-200.

38 SuÁrez, F., De legibus III, c. II, n. 6. La residencia natural del poder en la comunidad puede sugerir que una especie de democracia directa es la forma de gobierno natural. Sin embargo, Suárez duda que el poder haya existido o permanecido distributivamente en la comunidad. Ver SuÁREz, F., De legibus III, c. II, n. 5.

39 «Ad regimen et conservationem civilis societatis humanae non est absolute necessarius unus monarcha (sunt enim alii modi regiminum sufficientes, licet fortasse non ita perfecti [...]), et ideo cum de uno principatu politico loquimur, unum tribunal, seu potestatem unam intelligimus, sive illa in una naturali persona, sive in uno consilio, seu congregatione plurium tanquam in una persona ficta, ut in uno capite existat»: SuÁrEz, F., Defensio fidei III, c. 1, n. 5.

40 Ibid., III, c. 2, n. 7. La traducción es propia.

41 Ver ibid., III, c. 2, n. 8.

42 "[...]quod regimen talis reipublicae, vel provincie sit monarchicum, est ex hominum institutione [...] ergo principatus ipse est ab hominibus», en: SuÁrEz, F., De legibus III, c. IV, n. 5. 
político mediante el cual «el pueblo entregó el poder con la carga y la obligación de gestionar el cuidado del estado y administrar justicia; entonces, el príncipe (princeps) aceptó tanto la potestad como la condición» ${ }^{43}$. En virtud del carácter contractual de esta primera traslación del poder surge un título de gobierno, es decir, un derecho civil y positivo para dominar a otros, pues «no puede hallarse en ningún hombre autoridad para gobernar sin un título justo» ${ }^{44}$. Tras ese primer pacto social, dicho título se transmite de un soberano a otro garantizando la continuidad del estado. La transmisión del poder es estable y perpetua; no hace falta refrendar el pacto originario ${ }^{45}$ siempre y cuando (i) la comunicación del título se realice según las costumbres y leyes humanas de la comunidad, y (ii) el soberano no falte a las condiciones del pacto -i.e. no desatienda el bien de la comunidad ni su deber judicial— ${ }^{46}$. Suárez únicamente reconoce como mecanismos para la transmisión de estos título la sucesión legítima ${ }^{47}$ y la guerra justa iniciada por quien ya gobierna con títulos legítimos ${ }^{48}$. En ambos casos, empero, el fundamento último de la transmisión es el contrato social original ${ }^{49}$. Dicho contrato es lo que justifica que el heredero sea el nuevo sujeto del consentimiento y se obligue a las condiciones de aquél o, bien, es lo que legitima al vencedor de una guerra justa para gobernar sobre otros reinos a manera de ampliación de su propio dominio o como una pena justa para la comunidad sometida.

\section{LA MUJER POSEE UNA CAPACIDAD NATURAL PARA GOBERNAR}

Con base en la filosofía de Francisco Suárez debe afirmarse que la mujer posee una capacidad natural para gobernar. Todos los seres humanos poseen por naturaleza la capacidad para el dominio en virtud de haber sido creados a imagen y semejanza de Dios. Dado que la mujer participa por completo de la naturaleza humana y es tan semejante a Dios como el varón, en consecuencia, la mujer posee

43 SuÁrez, F., Defensio fidei III, c. 2, n. 12.

44 Ibid., III, c. 8, n. 1.

45 Ver ibid., III, c. 2, n. 19; SuÁrez, F., De legibus III, c. IV, n. 11.

46 Para una exposición más detallada de la teoría suareciana de la traslación del poder, ver CAStaño, S. R., «La teoría de la traslación del poder en Suárez, entre tradición y ruptura», en: Scripta Mediaevalia vol. 8, núm. 2, 2015, pp. 93-114.

47 Ver Suárez, F., De legibus III, c. IV, n. 3. «En el caso de la sucesión hereditaria, el poder no fue sólo dado a la persona, sino a la descendencia»: CASTAÑo, S. R., "Legitimidad y títulos de poder», en: La gravitación moral de la ley según Francisco Suárez, Juan CRuz Cruz (ed.), Eunsa, Pamplona 2009, p. 129.

${ }^{48}$ Ver SuÁrez, F., Defensio fidei III, c. 2, n. 20; Suárez, Francisco, De legibus III, c. IV, n. 4. Cf. ibid., III, c. II, n. 6. En el caso de una guerra injusta, el rey es un usurpador y no tiene verdadera potestad. Sin embargo, con el paso del tiempo, el pueblo puede dar su asentimiento al rey o a sus sucesores confiriendo así al soberano un título legítimo y tornando el poder de conquista en poder político. SuÁrez, F., Defensio fidei III, c. 5, nn. 7 y 12. «Así, pues, los títulos originados en la guerra son justos por verdadero derecho de conquista o se hacen justos por el consenso de la república ocupada "a través de un legítimo tiempo". Aparece con ello un título fundado en la prescripción»: Castaño, S. R., "Legitimidad y títulos de poder», en: La gravitación moral de la ley según Francisco Suárez, Juan Cruz Cruz (ed.), Eunsa, Pamplona 2009, p. 129.

49 «regium principatum et obedientiam illi debitam fundamentum habere in pacto societatis humanae»: SuÁrez, F., Defensio fidei III, c. 2, n. 11. 
una facultad racional e intelecto que le confiere la posibilidad de dominio, soberanía y de aprender a obrar según las artes ${ }^{50}$. Luego es evidente que para Suárez la mujer no es incapaz de dominio ${ }^{51}$.

Contra esto puede aducirse que en diferentes lugares Suárez afirma que el varón es la cabeza de la mujer y posee una potestad natural sobre ella, ya que ésta fue creada para el varón y por el varón ${ }^{52}$. Si por naturaleza la mujer no es capaz siquiera de mandar sobre el varón, ¿cómo es posible que Suárez defienda la aptitud natural de la mujer para gobernar a toda una comunidad? Para responder a esto conviene precisar, primero, que la condición de inferioridad de la mujer respecto del varón no es producto de una naturaleza inferior del género femenino. Ciertamente, Suárez habla de una excelencia particular del varón respecto de la mujer, la cual se manifestó desde el inicio de los tiempos en Adán, quien tuvo un intelecto más perfecto que Eva — signo de ello, cree Suárez, es que ella tuvo mayor dificultad para comprender la orden de Dios de no comer del árbol de la vida-53. Con todo, este rasgo varonil no es producto de una naturaleza superior, sino de un uso más notable de sus capacidades humanas. La diferencia entre varón y mujer es una cuestión de competencia en el uso de las capacidades que ambos comparten por igual. El uso subóptimo que las mujeres hacen de sus propias facultades es ocasionado por su propia fisiología, pues la mayor humedad ${ }^{54}$ de sus cuerpos las hace más susceptibles de ser afectadas por los movimientos de su sensibilidad y sus pasiones ${ }^{55}$. Se trata de una mera diferencia en la intensidad con que se usa una misma facultad natural, la cual, además, puede subsanarse políticamente si el rey - pues también hay reyes poco prudentes- o la reina se apoyan en la opinión de los sabios $^{56}$. Al margen de este condicionamiento material, Suárez defiende una igualdad natural tan grande que incluso adscribe a la mujer una facultad reproductiva activa análoga a la del varón ${ }^{57}$ y no encuentra motivos para excluir a las mujeres del grupo de notables de la comunidad (major pars populi) ${ }^{58}$. De esta manera, varón y mujer comparten una misma naturaleza cuya divergencia en la intensidad con que usan sus capacidades no comporta una diferencia esencial ni cancela la capacidad de dominio en las mujeres. En segundo lugar, debe afirmarse

50 «Quia etiam foemina est capax dominii, et principatus, et artificialia operari novit, et (quod caput est) habet facultatem rationalem, et intellectualem, secundum quam praecipue ratio imaginis attenditur: ergo etiam ipsa est ad imaginem», en: SuÁREz, F., De opere sex dierum III, c. 8, n. 22.

51 «Beatam Virginem habuisse jus haereditarium ad regnum Judaeorum, quia linea recta descendebat ex familia David, et deficiente viro, femina haereditate succedebat [...]; neque enim est cur ab hac generali lege excipiatur regia haereditas, cum neque in tota lege cautum sit, neque femina sit incapax regni, ut per se manifestum est»: SuÁrez, F., De incarnatione, disp. XLVIII, sect. I, n. 1. (Opera omnia, París, Vivès, 1860, t. 17).

52 Ver Suárez, F., Mysteria vitae Christi I, III, 4; SuÁrez, F., De opere sex dierum III, c. 18, n. 17 y SuÁrez, F., De legibus III, c. II.

53 Ver SuÁREZ, F., De opere sex dierum IV, c. 9, n. 9

54 Ver SuÁrez, F., Commentaria una cum quaestionibus in libros Aristotelis De anima. Ed. Ed. Salvador Castellote Cubells, Labor, Madrid 1992. d. 7, q. 16, n. 7.

55 Ver ibid., d. 11, q. 2, n. 11; SuÁrez, F., De actibus qui vocantur passiones d. I, c. X, n. 5 (Opera omnia, París, Vivès, 1856, t. 4).

56 Ver SuÁrez, F., De legibus III, c. IX, n. 8.

57 Ver SuÁrez, F., De anima d. 4, q. 9, n. 1.

58 Ver Suárez, F., De legibus VIII, c. X, n. 14. 
que la aparente inferioridad natural de la mujer respecto del varón comporta un precepto positivo que ordenara al varón gobernar o prohibiera a la mujer hacerlo, pues la sola naturaleza racional no es ley $^{59}$. Ciertamente, la naturaleza humana es la base de la moralidad, pero ella no constituye la honestidad o malicia de los actos, no dirige ni ilumina ni obliga. En sentido estricto, la razón natural es lo que discierne las cosas que son conformes a esa naturaleza y lo que las manda o prohíbe. Luego la sola anterioridad de la masculinidad respecto de la feminidad no es ningún tipo ley, pues de ello no se desprende la orden de que el varón gobierne ni la prohibición para que una mujer lo haga.

Dicho lo anterior, puede colegirse que el dominio natural del varón sobre la mujer tan sólo revela que la mujer es incapaz de dominio doméstico - y eso sólo en comparación con un varón adulto, pues ante la falta de uno, la mujer tiene pleno gobierno económico sobre los hijos y esclavos-, mas no que sea incapaz de dominio político, servil ni mucho menos de propiedad. Conceder semejante idea sería absurdo, pues sería consentir que la mujer tiene una capacidad natural, pero que está naturalmente impedida para poseerla específicamente — como si se dijera que posee una capacidad para razonar, pero que no es susceptible de tener intelecto y sensación-. Luego no hay nada en la naturaleza femenina que repugne su capacidad de dominio político, pero no de dominio doméstico, entre otras cosas, porque la razón o fundamento del que nace cada uno de estas potestades es muy distinta: en el primer caso, es la anterioridad causal del varón respecto de la mujer — aunado a su mejor despliegue de capacidades-; en el otro, es la voluntad de los ciudadanos congregados para vivir en comunidad. Si una mujer recibe legítimamente el poder político sobre una comunidad, no puede transferirlo a su marido - a pesar de estar sometida a él en el hogar-, ya que aquél no lo recibió de la comunidad ni según sus costumbres. Así «la reina por el matrimonio no [1] transfiere el reino a su marido abdicando en favor de él; [2] ni tampoco se lo confiere al marido para que esté en ambos por igual; [3] ni ella conserva la propiedad dándole al marido la administración. Por tanto [la reina] conserva en sí sola ambas cosas, a saber, el poder y la administración, y así puede ejercer por sí el mismo dominio de jurisdicción que antes [de casarse] y, por consiguiente, dar leyes ${ }^{60}$.

Aunque todo ser humano posee la capacidad natural para gobernar, sin embargo, ninguno posee por naturaleza el título para ejercer el dominio de jurisdicción de una comunidad. Dios es el fundamento último del dominio político, pero no lo otorgó mediante una acción o concesión especial para unos cuantos hombres. Por el contrario, Dios confirió el poder político como una propiedad común a todo el género humano, la cual resulta naturalmente cuando los individuos se unen políticamente formando una comunidad perfecta ${ }^{61}$. Los miembros de la comunidad

59 Sebastián Contreras se refiere a esto como el carácter antinatural de la ley natural en Suárez, en oposición a su carácter racional y práctico. Ver ConTrerAs, S., «Suárez, el derecho natural y la crítica contemporánea», en: Tópicos: Revista de Filosofía, núm. 53 (2017), pp. 255-272.

60 SuÁrez, F., De legibus III, c. IX, n. 10.

${ }_{61}$ Sergio Raúl Castaño denomina resultancia natural a la eficiencia causal que produce a esta potestad. El nombre es atinado, pues refiere a la causalidad que las formas sustanciales tienes respecto de sus potencias; por ejemplo, el alma respecto de sus potestades. Ver CASTAÑo, S. R., «Legitimidad y títulos de poder", en: La gravitación moral de la ley según Francisco Suárez», Juan CRUZ CRUZ (ed.), Eunsa, Pamplona 2009, p. 124. 
pueden elegir congregarse o no, pero si deciden hacerlo no pueden contravenir la necesidad de que la comunidad sea gobernada por una instancia ${ }^{62}$. Luego el dominio político no es una realidad que dependa del arbitrio de los ciudadanos, sino una propiedad natural del conjunto de hombres moralmente unidos y, por ende, no reside en ninguno de ellos, sino en la corporación. «[C]uando [el poder civil] se encuentra en un hombre o soberano por un título legítimo y por un derecho normal (ordinare iure), es que ha dimanado del pueblo y de la comunidad, sea próxima sea remotamente, y no puede tenerse de otra manera para que sea justo ${ }^{63}$. Ni Dios ni la naturaleza humana determinan en quién o quiénes reside el título para ejercer dicho poder político; más bien, se trata de una institución humana que depende, exclusivamente, de la voluntad de los miembros de una comunidad y de sus costumbres.

En resumen, la capacidad de dominio político es natural a todos los seres humanos, con independencia de su género. Dios dio a los seres humanos el poder de gobernar y crear leyes "a manera de una propiedad que se sigue de la naturaleza» ${ }^{64}$ La potestad para gobernar es una propiedad que surge tan pronto los individuos se agrupan en una corporación, ya es esencial para la conservación de la comunidad ( $\sin$ los deseos de que cada uno de los individuos). No obstante, la naturaleza humana no determina quién debe ejercer el dominio sobre la comunidad, sino que eso compete a las leyes humanas.

\section{El POder de una mujer para gobernar Es Un DERECHO Natural; EL TÍTULO PARA EJERCERLO ES UN DERECHO CIVIL}

Francisco Suárez distingue que el término derecho (ius) a veces significa una facultad o poder moral, pero otras significa ley. De acuerdo con el primer sentido, se habla del derecho que el dueño de una cosa tiene sobre ella o del derecho de un obrero a su salario. A estos iura Suárez también los llama derechos reales o útiles, pues refieren a una auténtica acción o dominio «que cada uno tiene sobre lo suyo o sobre lo que se le debe» ${ }^{65}$. El derecho entendido de esta manera constituye el objeto propio de la justicia, ya que si la justicia es dar a cada quien lo que le pertenece, entonces la justicia consiste en dar a cada quien su derecho. En cambio, Suárez denomina al segundo sentido de ius como derecho legal o útil. Dicho sentido es el que se emplea, por ejemplo, en la oposición entre ignorancia del derecho e ignorancia del hecho. Suárez considera impropio entender ius como ley o norma del bien obrar, pues es una denominación que concierne más al efecto de la ley que a la esencia misma de la ley "porque la ley determina la equidad o es su medida y su regla, pero no es propiamente la equidad misma ${ }^{66}$. En cualquier caso, los dos significados del término derecho se armonizan en la medida en que las potestades morales pueden existir si y sólo si existe una ley que prohíbe a los otros transgredirlas. Ambos derechos

62 Ver ibid., pp. 123-136.

63 SuÁrez, F., De legibus III, c. IV, n. 2.

64 Ibid., III, c. III, n. 5.

65 Ibid., I, c. II, n. 5.

66 Ibid., I, c. II, n. 6. 
pueden dividirse en natural, de gentes y civil. Sin embargo, conviene tener presente que cuando Suárez refiere a cualquiera de estas clases de derechos lo hace en tanto clases de ley, es decir, como la colección de preceptos naturales, de gentes o civiles ${ }^{67}$.

Una cosa o acción puede ser de derecho natural de distintas maneras ${ }^{68}$. En primer lugar, Suárez admite que algo puede pertenecer positivamente al derecho natural cuando la ley natural lo manda o lo prohíbe. «Para ello se requiere que la razón natural, considerada en sí misma, dicte que tal cosa es necesaria para la honestidad moral, ya lo dicte sin necesidad de razonamientos, ya recurriendo a un razonamiento o a varios ${ }^{69}$. En segundo lugar, algo puede pertenecer al derecho natural negativa o permisivamente cuando la ley natural ni lo manda ni lo prohíbe, sino que lo permite o tolera. Entre las cosas que pertenecen al derecho natural de esta manera, Suárez incluye tanto aquellas que son indiferentes a la naturaleza humana como aquellas para las cuales el ser humano tiene cierta inclinación o disposición, pero sobre las que no se pronuncia ningún precepto natural. Suárez, por ejemplo, cree que la propiedad privada pertenece negativamente al derecho natural en la medida en que no existe un precepto que la censure o, en su defecto, que ordene conservar el estado comunitario (i.e. res nullae) y original de las $\operatorname{cosas}^{70}$, y algo semejante considera respecto de la esclavitud. Suárez añade que una algo puede decirse de derecho natural de una tercera manera cuando ésta tiene su fundamento en la condición natural de las cosas, pero no es ordenado absolutamente (fundamentum habet in conditione naturali, licet non simpliciter praecipiatur iure naturali). Suárez ilustra estas realidades con el hecho de que un hijo pueda heredar al padre sin testamento. Aunque parece ambiguo este criterio, lo que Suárez tiene en mente son las cosas o acciones a las que la naturaleza inclina y que pueden inferirse inmediatamente con la razón natural.

Prima facie, el dominio de jurisdicción o potestad política es una potestad moral que poseen todos los seres humanos por derecho natural; una inclinación humana que descansa en su propia naturaleza y semejanza divina. El dominio político es un derecho natural de los seres humanos porque su naturaleza social los impele a vivir en comunidad y ésta precisa que algún(os) miembro(s) ostente una potestad política sobre los demás para poder conservarse ${ }^{71}$. Este derecho se expresa en los individuos a manera de un título que les permite desplegar una capacidad innata a todos.

El título por el que algún ser humano está facultado para ejercer su dominio político es otorgado por el arbitrio de los hombres. Aunque el dominio político surge

67 Ver ibid., II, c. XVII, n. 2.

68 Ver ibid., II, c. XIV, nn. 6 y 14.

${ }^{69}$ Ibid., II, c. XIV, n. 6. Adicionalmente, Suárez distingue entre las cosas prescritas por la ley natural que dependen del arbitrio humano (v.gr. vigilar los contratos promesas) y las que no (v.gr. los deberes para Dios y o los padres). Suárez considera que el derecho humano, únicamente, puede dispensar los preceptos del derecho natural que en su obligación dependen de un previo consentimiento, pero sólo en los casos en que la materia del voto o promesa se altera. Ver ibid., II, c. XIV, n. 11 .

70 Ver Ibid., II, c. XIV, nn. 14 ss. Cf. Artículo propio,

71 En última instancia, la sociabilidad y aptitud natural del ser humano para gobernar y obedecer a otros procede de Dios mismo, en tanto autor de la naturaleza. Ver SuÁREz, F., Defensio fidei III, c. 1, n. 7 y SuÁrez, F., De legibus III, c. III, n. 2. 
de la naturaleza humana, el título por el cual se ostenta dicho poder es producto de una especie de pacto entre la comunidad y el soberano ${ }^{72}$. Para que la traslación sea legítima debe realizarse en algún modo debido, a saber, por consentimiento, sucesión o conquista. La forma solemne en que el consentimiento es recogido, las condiciones para la sucesión y la legitimación de una guerra son establecidas por las leyes humanas. Luego no existe un derecho natural a ostentar el título para ejercer el dominio político, ni mucho menos un mandato positivo de la ley natural que dicte cómo debe realizarse la traslación del dominio político al soberano, sino que la voluntad humana establece a quién y cómo se transfiere el dominio.

A pesar de todo, Suárez concede que la naturaleza humana inclina a un cierto tipo de constitución, forma de traslación y sujeto del dominio. Suárez no duda en mostrar su deferencia por la monarquía como la mejor forma de gobierno ${ }^{73}$. Asimismo, Suárez tampoco esconde su deferencia hacia la elección como el medio más conveniente para elegir al príncipe. No sólo considera esta vía la más racional, sino también la que expresa de mejor manera la voluntariedad en la institución del gobierno de la comunidad ${ }^{74}$. Finalmente, Suárez admite que existe una cierta inclinación humana a que el soberano sea varón, pues se presume una mayor prudencia de su parte porque hace un uso más competente de sus facultades y posee una mayor firmeza (firmitas) ante los movimientos sensibles e irracionales del alma. En cualquier caso, debe reconocerse que la propensión natural a la monarquía elegida democráticamente y encabezada por un varón no basta para presumir que alguno de estos elementos pertenece al derecho natural, pues eso convertiría a las otras alternativas en algo perverso o inconveniente. «El derecho natural comprende todos los preceptos o principios morales que tienen una evidente honestidad tan necesaria para la rectitud moral que sus contrarios contienen evidentemente desorden o malicia moral ${ }^{75}$. A lo sumo debe considerarse que pertenecen de manera negativa al derecho natural en la medida en que no existe un mandato natural o, mejor dicho, que pertenecen al derecho de gentes — también llamado derecho natural secundario-, pues no comportan una conveniencia a la naturaleza humana simpliciter, sino en tanto inscrita a una comunidad política.

A la luz de lo anterior debe afirmarse, entonces, que el derecho de una mujer a heredar el título para ejercer su capacidad natural de dominio ciertamente es derecho natural, pero que pertenece de manera negativa — no inclinativa, como en el caso del varón-, en tanto que no existe un mandato natural que lo prohíba ni una orden que lo mande ${ }^{76}$. Este modo de pertenecer al derecho natural, empero, es suficiente para conferirle un reclamo (ius ad aliquod) debido a que se trata de un acto

72 Ver SuÁREz, F., Defensio fidei III, c. 2, n. 11.

73 SuÁrez, F., De legibus III, c. IV, n. 1.

74 Ver SuÁrez, F., Defensio fidei III, c. 2, nn. 12, 19 y 20.

75 SuÁrez, F., De legibus II, c. VII, n. 4.

76 "[Suárez] explained that permissive natural law could not allow any conduct that was evil in itself but it could define a sphere of natural rights where humans were free to act as they chose. [.. .] Permissive law could not be wholly separated from preceptive and prohibitory law, he argued. Hence, while permissive natural law allowed the exercise of certain rights, preceptive natural law protected those rights against violation by others»: TIERnEY, B., "Natural Law and Natural Rights. Old Problems and Recent Approaches», en: The Review of Politics, vol. 64, núm. 3, 2002, p. 403. 
bueno $^{77}$. Sin embargo, las costumbres de los distintos reinos han establecido que la cabeza de la comunidad debe ser un varón, siguiendo una cierta inclinación natural fincada en la mayor prudencia del varón. Luego para que una mujer reciba el título que la faculte a ejercer su dominio político, el del derecho civil debe mandarlo a manera de una dispensa del derecho de gentes que prima en los diferentes reinos. Las leyes humanas pueden dispensar los preceptos del derecho natural secundario (i.e. derecho de gentes), es decir, de los preceptos que en su obligación preceptiva dependen de un previo consentimiento de la voluntad humana y de la eficacia de ese consentimiento para hacer algo. Luego, aunque existe un derecho natural a que la mujer gobierne -i.e. no existe ningún impedimento natural que la mujer lo haga-, el derecho humano es lo que introduce la posibilidad de que una mujer pueda heredar o recibir de la comunidad el dominio político. Dicho derecho es una concesión de la ley natural primaria y una dispensa a la inclinación humana recogida en las costumbres del derecho de gentes, la cual se realiza, únicamente, en determinadas comunidades que así lo legislan y bajo determinadas circunstancias excepcionales, a saber, ante la ausencia de un heredero legítimo varón o ante la minoría de edad del heredero.

\section{Conclusiones}

Para Francisco Suárez, todos los seres humanos poseen la capacidad natural de mandar en virtud de haber sido creados a imagen y semejanza de Dios. Algunos seres humanos poseen el derecho o potestad a ejercitar esa capacidad natural por haberlo recibido del pueblo mediante algunas de las formas legítimas de traslación. Si un individuo (varón o mujer) no gobierna no es porque carezca de la capacidad para hacerlo, sino porque carece del título para desplegar su capacidad natural. Cuando alguien (varón o mujer) ostenta el derecho a gobernar, empero, no existe ningún impedimento para que ejercite y use plenamente su facultad moral.

Luego por naturaleza la mujer está capacitada para gobernar y puede hacerlo de manera plena, siempre y cuando, reciba el derecho o facultad de dominio político por parte de la comunidad. Esto es posible siempre que las leyes humanas así lo estipulen. No existe ningún impedimento natural para que una mujer gobierne. Lo que ha prevenido a las mujeres de gobernar son las costumbres mediante las cuales las distintas comunidades otorgan el dominio político a los varones. Dichas costumbres que asumen como conveniente ser gobernadas por un varón no son arbitrarias, sino que responden a ciertas notas de la naturaleza humana que sugieren que la fisiología femenina afecta el modo en que usa sus facultades. Sin embargo, la interferencia que puede producir la condición corporal de la mujer no le impide en absoluto ejercer competentemente todas sus facultades, incluida el dominio en cualesquiera de sus tipos.

77 Para un estudio más profundo acerca de si la ley permisiva es auténtica ley, si la permisión es un efecto de la ley y sobre los distintos tipos de permisión, ver Amezúa Amezúa, L. C., «Efectos de las normas jurídicas según Francisco Suárez», en: Revista Jurídica Digital UANDES, vol. 2, núm. 1, 2018, pp. 92-104. 


\section{BiBLIOGRAFÍA}

Amezúa Amezúa, L. C. (2018). «Efectos de las normas jurídicas según Francisco Suárez», en: Revista Jurídica Digital UANDES, vol. 2, núm. 1, pp. 92-104.

Castaño, S. R. (2015). «La teoría de la traslación del poder en Suárez, entre tradición y ruptura», en: Scripta Mediaevalia vol. 8, núm. 2, pp. 93-114.

Castaño, S. R. (2009). "Legitimidad y títulos de poder», en: La gravitación moral de la ley según Francisco Suárez, Juan Cruz Cruz (ed.). Pamplona: Eunsa, p. 129.

Castilla Urbano, F. (1995). «El concepto de "estado de naturaleza" en la escolástica española de los Siglos XVI y XVII», en: Anuario filosófico, núm. 12, pp. 425-445.

Contreras, S. (2017). «Suárez, el derecho natural y la crítica contemporánea», en: Tópicos: Revista de Filosofía, núm. 53, pp. 255-272.

Doyle, J. "Suárez on Human Rights», en: Collected Studies on Francisco Suárez, S.J, (15481617), Victor M. Salas (ed.). Leuven: Leuven University Press, p. 350.

Faraco, C. (2017). «Faciamus hominem: reflexión sobre el libro V del Tractatus de opere sex dierum de Suárez», en: Cauriensia, vol. 12, pp. 153-168.

Font Oporto, P. (2018). «La facticidad de la filosofía política de Francisco Suárez: un camino hacia otra Modernidad», en: Pensamiento. Revista de Investigación e Información Filosófica, vol. 74, n. 279 Extra. Pp. 179-200.

Gaetano, M. T., «What Kind of Corporeal or Political Life Men Would Have Professed in the State of Innocence», en: Journal of Markets \& Morality, vol. 15, núm. 2, pp. 527-563.

Ibáñez Ruiz del Portal, E. (2018). «Francisco Suárez y los derechos humanos. Corrientes historiográficas y perspectivas críticas actuales», en: Pensamiento, Revista de Investigación e Información Filosófica, vol. 74 núm. 279 Extra. Pp. 221-235.

Suárez, F. (1856). De actibus qui vocantur passiones (Opera omnia., París: Vivès, t. 4).

Suárez, F. (1992). Commentaria una cum quaestionibus in libros Aristotelis De anima. Ed. Ed. Salvador Castellote Cubells. Madriod: Labor, 3 vol., Castellote, vol. I, III vols. Labor, Madrid, 1978, pp. XXXVIII.

Suárez, F. (1860). De incarnatione (Opera omnia. París: Vivès, t. 17).

Suárez, F. (1856). De opere sex dierum (Opera omnia. París: Vivès, t. 3).

Suárez, F. (1859). De statu perfectionis et religionis (Opera omnia. París: Vivès, t. 15)

Suárez, F. (1859). De virtute et statu religionis (Opera omnia. París: Vivès, t. 13).

Suárez, F. (1859). Defensio fidei Catholicae adversus anglicanae sectae errores (Opera omnia. París: Vivès, t. 24)

Suárez, F. (1860). Mysteria vitae Christi (Opera omnia. París: Vivès, t. 19)

Suárez, F. (1856). Tractatus de legibus ac Deo legislatore (Opera omnia. París: Vivès, t. 5).

Tierney, B. (2002). «Natural Law and Natural Rights. Old Problems and Recent Approaches», en: The Review of Politics, vol. 64, núm. 3, p. 403.

[Artículo aprobado para publicación en febrero de 2020] 